\title{
Rapid genotyping of common deficient thiopurine $S$-methyltransferase alleles using the DNA-microchip technique
}

\author{
Tatyana V Nasedkina*,1, Olga E Fedorova ${ }^{1}$, Andrei S Glotov ${ }^{1}$, Natalia V Chupova ${ }^{2}$,
} Elena V Samochatova ${ }^{2}$, Olga A Maiorova ${ }^{2}$, Valeria V Zemlyakova ${ }^{2}$, Anastasia E Roudneva ${ }^{2}$, Alexander V Chudinov ${ }^{1}$, Roman A Yurasov ${ }^{1}$, Janna M Kozhekbaeva ${ }^{1}$, Victor E Barsky ${ }^{1}$, Eugene Y Krynetskiy ${ }^{3,4}$, Natalia F Krynetskaia ${ }^{4}$, Cheng Cheng ${ }^{3}$, Raul C Ribeiro ${ }^{3}$, William E Evans ${ }^{3,4}$, Alexander G Roumyantsev ${ }^{2}$ and Alexander S Zasedatelev ${ }^{1}$

${ }^{1}$ Engelhardt Institute of Molecular Biology of the Russian Academy of Sciences, Moscow, Russia; ${ }^{2}$ Research Institute of Pediatric Hematology, Moscow, Russia; ${ }^{3}$ St Jude Children's Research Hospital, Memphis, TN, USA; ${ }^{4}$ University of Tennessee, Memphis, TN, USA

Thiopurine drugs are metabolized, in part, by $S$-methylation catalyzed by thiopurine $S$-methyltransferase (TPMT). Patients with very low or undetectable TPMT activity are at high risk of severe, potentially fatal hematopoietic toxicity when they are treated with standard doses of thiopurines. As human TPMT activity is controlled by a common genetic polymorphism, it is an excellent candidate for the clinical application of pharmacogenetics. Here, we report a new molecular approach developed to detect point mutations in the TPMT gene that cause the loss of TPMT activity. A fluorescently labeled amplified DNA is hybridized with oligonucleotide DNA probes immobilized in gel pads on a biochip. The specially designed TPMT biochip can recognize six point mutations in the TPMT gene and seven corresponding alleles associated with TPMT deficiency: TPMT ${ }^{*}$; TPMT*3A, TPMT ${ }^{*} 3 B, T P M T^{*} 3 C, T P M T^{*} 3 D, T P M T^{*} 7$, and $T P M T^{*} 8$. The effectiveness of the protocol was tested by genotyping 58 samples of known genotype. The results showed $100 \%$ concordance between the biochip-based approach and the established PCR protocol. The genotyping procedure is fast, reliable and can be used for rapid screening of inactivating mutations in the TPMT gene. The study also provides the first data on the frequency of common TPMT variant alleles in the Russian population, based on a biochip analysis of 700 samples. TPMT gene mutations were identified in 44 subjects; genotype ${ }^{*} 1 /{ }^{*} 3 \mathrm{~A}$ was most frequent.

European Journal of Human Genetics (2006) 14, 991-998. doi:10.1038/sj.ejhg.5201647; published online 17 May 2006

Keywords: thiopurine S-methyltransferase ; oligonucleotide biochip; diagnostics; pharmacogenetics

*Correspondence: Dr TV Nasedkina, Engelhardt Institute of Molecular Biology, 32 Vavilov St, Moscow 119991, Russia.

Tel: + 7095135 6259; Fax: + 7095135 1405;

E-mail: nased@eimb.ru

Received 10 November 2005; revised 27 February 2006; accepted 28 March 2006; published online 17 May 2006
Introduction

Thiopurine $S$-methyltransferase (TPMT, EC 2.1.1.67) is a cytosolic enzyme that catalyzes $S$-methylation of thiopurines such as 6-mercaptopurine (6-MP) and 6-thioguanine. ${ }^{1,2}$ These drugs are used in the treatment of acute lymphoblastic leukemia, rheumatoid arthritis and autoimmune hepatitis, as well as in organ transplantation, ${ }^{3-6}$ and most of their nucleotide metabolites undergo 
$S$-methylation by TPMT. ${ }^{1,6}$ Approximately one in 300 persons $(0.3 \%)$ have low or undetectable TPMT enzyme activity, and TPMT activity is intermediate in about $10 \%$ of the population. ${ }^{2}$ Patients with very low or undetectable TPMT activity are at high risk of severe, potentially fatal hematopoietic toxicity when they are treated with standard doses of thiopurines. ${ }^{5-6}$

Recent studies have established that TPMT enzyme activity is altered by variations in the TPMT gene., ${ }^{5-8}$ TPMT resides on chromosome band $6 \mathrm{p} 22.3$ and has 10 exons, eight of which encode the $28-\mathrm{kDa}$ TPMT protein. ${ }^{9}$ Approximately 20 variant human alleles are associated with decreased TPMT catalytic activity. ${ }^{8}$ These variants result from point mutations in the TPMT open-reading frame or at intron/exon splice sites. The wild-type allele, $T P M T^{*} 1$, encodes active TPMT. TPMT*2 $(238 \mathrm{G}>\mathrm{C})$, $T P M T * 3 A(460 \mathrm{G}>\mathrm{A}, 719 \mathrm{~A}>\mathrm{G})$ and $T P M T^{*} 3 \mathrm{C}(719 \mathrm{~A}>\mathrm{G})$ are the most prevalent $(80-95 \%)$ of the polymorphic alleles that cause significantly reduced enzyme activity. ${ }^{10}$ $T P M T^{*} 3 B(460 G>A)$ is much more rare, whereas the remaining TPMT variants can be considered family-specific ('private') mutations found in individuals of various ethnic groups. ${ }^{11-14}$ The TPMT phenotype is determined by measuring erythrocyte TPMT enzyme activity, a procedure that is a standard clinical test in some centers. ${ }^{2,15}$ However, erythrocyte TPMT activity assays may be inaccurate if the patient has received, for example, a blood transfusion from a donor with normal TPMT activity within the previous 3 months. Genotyping has been proposed as a more reliable method for detecting TPMT deficiency, as exemplified by recent publication. ${ }^{16}$ First, following transfusion of erythrocytes, blood contains predominantly the host's DNA; alternatively, DNA extraction from other tissues (eg buccal epithelium cells) overcomes the problem of erroneous classification of samples.

The TPMT-gene variations can be detected by using allele-specific (AS)-PCR, PCR-restriction fragment length polymorphism (PCR-RFLP), ${ }^{10,17}$ or denaturing high-performance liquid chromatography. ${ }^{8}$ The most common targets for such analyses are well-studied TPMT alleles: ${ }^{*} 2,{ }^{*} 3 A$, and $* 3 C$. Because PCR-based genotyping is usually performed as several individual reactions, it is too laborious for use as a standard clinical test.

To standardize TPMT genotyping and make the procedure more suitable for clinical testing, we used the gelbased DNA-microchip technological platform. ${ }^{18}$ One of our goals was to develop and validate a rapid oligonucleotide microarray-based TPMT genotyping method. Another goal arose from the significant interethnic differences in the distribution of TPMT alleles worldwide. The very heterogeneous Russian population has not yet been studied for the presence of most clinically significant TPMT polymorphic alleles, whereas the clinical relevance of TPMT genotype can be assessed only in previously characterized populations. We therefore determined the frequencies of four common clinically significant TPMT alleles in the Russian population while validating the TPMT biochip by analyzing 700 clinical samples.

\section{Materials and methods Subjects}

Fifty-eight control samples of DNA were obtained from St Jude Children's Research Hospital, Memphis, TN, USA. Seven hundred peripheral blood samples were collected in the Research Institute of Pediatric Hematology (RIPH), Moscow, Russia, from unrelated individuals: 280 patients with lymphoproliferative disorders and 420 healthy volunteers or patients with various gastroenteric diseases. Most subjects were less than 18 years of age. The study had been approved by the Ethics Committee of the Research Institute of Pediatric Hematology (RIPH) in Moscow. Written informed consent was obtained from patients or their parents for the collection and use of samples.

\section{DNA extraction}

Genomic DNA was extracted from leukocytes of EDTAtreated peripheral blood by using the QIAmp DNA blood kit (Qiagen, USA), diluted in distilled water to a concentration of $1.25 \mathrm{ng} / \mu \mathrm{l}$, and stored at $-20^{\circ} \mathrm{C}$ until use.

\section{Target DNA}

The target DNA was prepared by two-round nested multiplex PCR. The first round of PCR amplification was performed in $25 \mu \mathrm{l}$ of multiplex mixture containing $1.5 \mathrm{U}$ Taq polymerase (Sileks, Russia), $0.2 \mathrm{~mm}$ each of dNTPs, a mixture of primers (10 pmol of each primer), $11 \mathrm{~mm}$ Tris$\mathrm{HCl}, \mathrm{pH} 8.3,55 \mathrm{mM} \mathrm{KCl}, 1.5 \mathrm{mM} \mathrm{MgCl}_{2}$, and $1 \mu \mathrm{l}$ of DNA template. PCR was carried out as follows: $5 \mathrm{~min}$ at $95^{\circ} \mathrm{C} ; 35$ cycles of $30 \mathrm{~s}$ at $95^{\circ} \mathrm{C} ; 30 \mathrm{~s}$ at $62^{\circ} \mathrm{C} ; 1 \mathrm{~min}$ at $72^{\circ} \mathrm{C}$; and extension at $72^{\circ} \mathrm{C}$ for $5 \mathrm{~min}$. The three pairs of primers (Table 1) in one tube amplified a 265-bp fragment (exon 5), a 371-bp fragment (exon 10) and a 694-bp fragment (exon 7 ) of the TPMT gene. The second round, an asymmetric PCR with fluorescently labeled primers, yielded a fluorescently labeled single-stranded target DNA. This reaction was performed in $25 \mu \mathrm{l}$ of multiplex mixture containing 1.5 U Taq polymerase, $0.2 \mathrm{~mm}$ each of dNTPs, a mixture of primers $(0.2 \mathrm{pmol}$ of unlabeled forward primer and $10 \mathrm{pmol}$ of labeled reverse primer), $11 \mathrm{~mm}$ Tris- $\mathrm{HCl}, \mathrm{pH} 8.3,55 \mathrm{~mm}$ $\mathrm{KCl}, 1.5 \mathrm{mM} \mathrm{MgCl}_{2}$ and $2 \mu \mathrm{l}$ of the first-round product. PCR was carried out as follows: $5 \mathrm{~min}$ at $95^{\circ} \mathrm{C}, 30$ cycles of $30 \mathrm{~s}$ at $95^{\circ} \mathrm{C}, 30 \mathrm{~s}$ at $63^{\circ} \mathrm{C}, 1 \mathrm{~min}$ at $72^{\circ} \mathrm{C}$, and extension at $72^{\circ} \mathrm{C}$ for $5 \mathrm{~min}$. During the second round, the three pairs of primers (Table 1) amplified a 160-bp fragment (exon 5), a 176-bp fragment (exon 10), and a 218-bp fragment (exon 7) of the TPMT gene. 
DNA oligonucleotide probes

Oligonucleotide probes were designed by using the program Oligo 5 (Molecular Biology Insights, Cascade, CO, USA). Oligonucleotides were synthesized in an ABI TM 394 DNA/RNA synthesizer (Applied Biosystems, Foster City, CA, USA) by the standard phosphoramidite method. All oligonucleotides were synthesized with an amino group at the $3^{\prime}$ - end by using 3'-Amino-Modifier C7 CPG (Glen Research, Sterling, VA, USA).

\section{Manufacture of biochips}

The gel-based microchips were formed by using photoinduced copolymerization as described. ${ }^{19}$ Oligonucleotide probes were immobilized in hemispherical hydrogel pads $150 \mu \mathrm{m}$ in diameter fixed to the hydrophobic surface of a microscope slide. ${ }^{18}$ Briefly, a solution of copolymerization mixture and modified oligonucleotide was transferred to each well of a 384-well microplate (Genetix, New Milton, UK) and spotted by a robot pin (QArray, Genetix, New Milton, UK) on the surface of the slide. The gel arrays were polymerized under UV light for $20 \mathrm{~min}$ at $20^{\circ} \mathrm{C}$ in dry nitrogen, then washed in double-distilled water and dried. For the additional information about analytical capabilities

Table 1 Primers used in two-round PCR

\begin{tabular}{|c|c|c|}
\hline Abbreviatior & Sequence $5^{\prime}-3^{\prime}$ & $\begin{array}{c}\text { Conc. } \\
(p m o l / \mu l)\end{array}$ \\
\hline F238(1) & AGTGTAAATGTATGATTTTATGCAGG & 10 \\
\hline R238(1) & TAAATAGGAACCATCGGACACAT & 10 \\
\hline F460(1) & САAGССТТАТАGССТТАСАСССАGG & 10 \\
\hline $\mathrm{R} 460(1)$ & AGGCAGCTAGGGAAAAAGAAAGGTG & 10 \\
\hline F719(1) & GAGACAGAGTTTCACCATCTTGG & 10 \\
\hline R719(1) & CAGGCTTTAGCATAATTTTCAATTCСТC & 10 \\
\hline F238(2) & AGTGTAAATGTATGATTTTATGCAGG & 10 \\
\hline *R238(2) & $\begin{array}{l}\text { Cy3- } \\
\text { ACAAGCСTTAAATACTTTGGTTCCAGG }\end{array}$ & 50 \\
\hline $\mathrm{F} 460(2)$ & CTCTTTCTGGTAGGACAAATATTGGC & 10 \\
\hline${ }^{*} \mathrm{R} 460(2)$ & $\begin{array}{l}\text { Cy3- } \\
\text { AAGTCTAAGCTGATTTTCTAGAACCCA }\end{array}$ & 50 \\
\hline $\begin{array}{l}F 719(2) \\
{ }^{*} R 719(2)\end{array}$ & 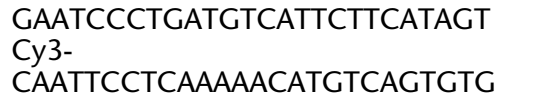 & $\begin{array}{l}10 \\
50\end{array}$ \\
\hline
\end{tabular}

of the method, biochip preparation and potential applications go to the web site www.biochip.ru.

\section{Design of the TPMT biochip}

The TPMT biochip contains a set of 12 oligonucleotide probes (Table 2) arrayed in six columns, each of which corresponds to a single-nucleotide substitution in a variable position. Each probe is presented in duplicate (eg, rows $A$ and $\mathrm{A}^{\prime}$ and $\mathrm{B}$ and $\mathrm{B}^{\prime}$ contain identical sets of probes) (Figure 1). The biochip can simultaneously detect six TPMT mutations that lead to the loss of TPMT catalytic activity (G238C, G292T, G460A, G644A, T681G and A719G) and indicate the seven corresponding mutant alleles $T P M T^{*} 2, T P M T^{*} 3 A$, $T P M T^{*} 3 B, T P M T^{*} 3 C, T M P T^{*} 3 D, T P M T^{*} 7$, and $T P M T^{*} 8$.

\section{Hybridization}

Hybridization mixture was prepared by adding $17 \mu$ l of the second-round PCR amplificate to $10 \mu \mathrm{l}$ of formamide and $13 \mu \mathrm{l}$ of $20 \times \operatorname{SSPE}(0.2 \mathrm{M}$ phosphate buffer, $\mathrm{pH} 7.4,2.98 \mathrm{M}$ $\mathrm{NaCl}, 0.02 \mathrm{M}$ EDTA). The total volume of $40 \mu \mathrm{l}$ usually containing $1-3 \mu \mathrm{g}$ of DNA was completely denatured at $94^{\circ} \mathrm{C}$ before hybridization, briefly cooled on ice, then applied to a microchip in a hybridization chamber (Cover Well ${ }^{\mathrm{TM}}$, Bioworld, Dublin, USA) and left overnight at $37^{\circ} \mathrm{C}$. The microchip was washed for $20 \mathrm{~min}$ with $40 \mathrm{ml}$ of $1 \times$ SSPE at room temperature and dried.

\section{Image analysis}

Fluorescence was measured with a portable chip analyzer equipped with CCD camera. $^{20}$ The dedicated software Imageware v1.1 developed at the Engelhardt Institute of Molecular Biology was used for data processing and image analysis.

\begin{tabular}{|c|c|c|c|c|c|c|}
\hline & 1 & 2 & 3 & 4 & 5 & 6 \\
\hline A & G238 & G292 & G460 & G644 & T681 & A719 \\
\hline$A^{\prime}$ & G238 & G292 & G460 & G644 & T681 & A719 \\
\hline B & $238 \mathrm{C}$ & $292 \mathrm{~T}$ & $460 \mathrm{~A}$ & $644 \mathrm{~A}$ & $681 G$ & $719 \mathrm{G}$ \\
\hline 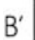 & $238 \mathrm{C}$ & $292 \mathrm{~T}$ & $460 \mathrm{~A}$ & $644 \mathrm{~A}$ & $681 \mathrm{G}$ & $719 \mathrm{G}$ \\
\hline
\end{tabular}

Figure 1 Scheme of biochip. Each column from one to six represents a set of probes for one variable position. Rows $A$ and $A^{\prime}$ contain the wild-type sequences; $B$ and $B^{\prime}$ contain the mutant sequences. Rows $A$ and $A^{\prime}$ and rows $B$ and $B^{\prime}$ are identical.

Table 2 Oligonucleotide probe sequences (+ strand) immobilized on the TPMT biochip

\begin{tabular}{cllll}
\hline Exon & SNP & Allele & Wild-type probe 5'-3' & Mutation probe 5'-3' \\
\hline 5 & G238C & $* 2$ & gcaggtttgcagaccgg & gcaggtttccagaccgg \\
4 & G292T & $* 3 \mathrm{D}$ & gggatacaagaattttttac & gggatacaataattttttac \\
7 & G460A & $* 8, * 3 \mathrm{~A}, * 3 \mathrm{D}$ & gatagaggagcattagttgc & gatagaggaacattagttgc \\
10 & G644T & $* 7$ & tgcaatatacgttgtcttgag & tgcaatatactttgtcttgag \\
10 & T681C & agaacgacataaaagttgg & gaacgacagaaaagttgg \\
10 & A719C & gaaaagttatatctacttacag & gaaaagttatgtctacttaca \\
\hline
\end{tabular}

Bold characters mark the variable nucleotides. 

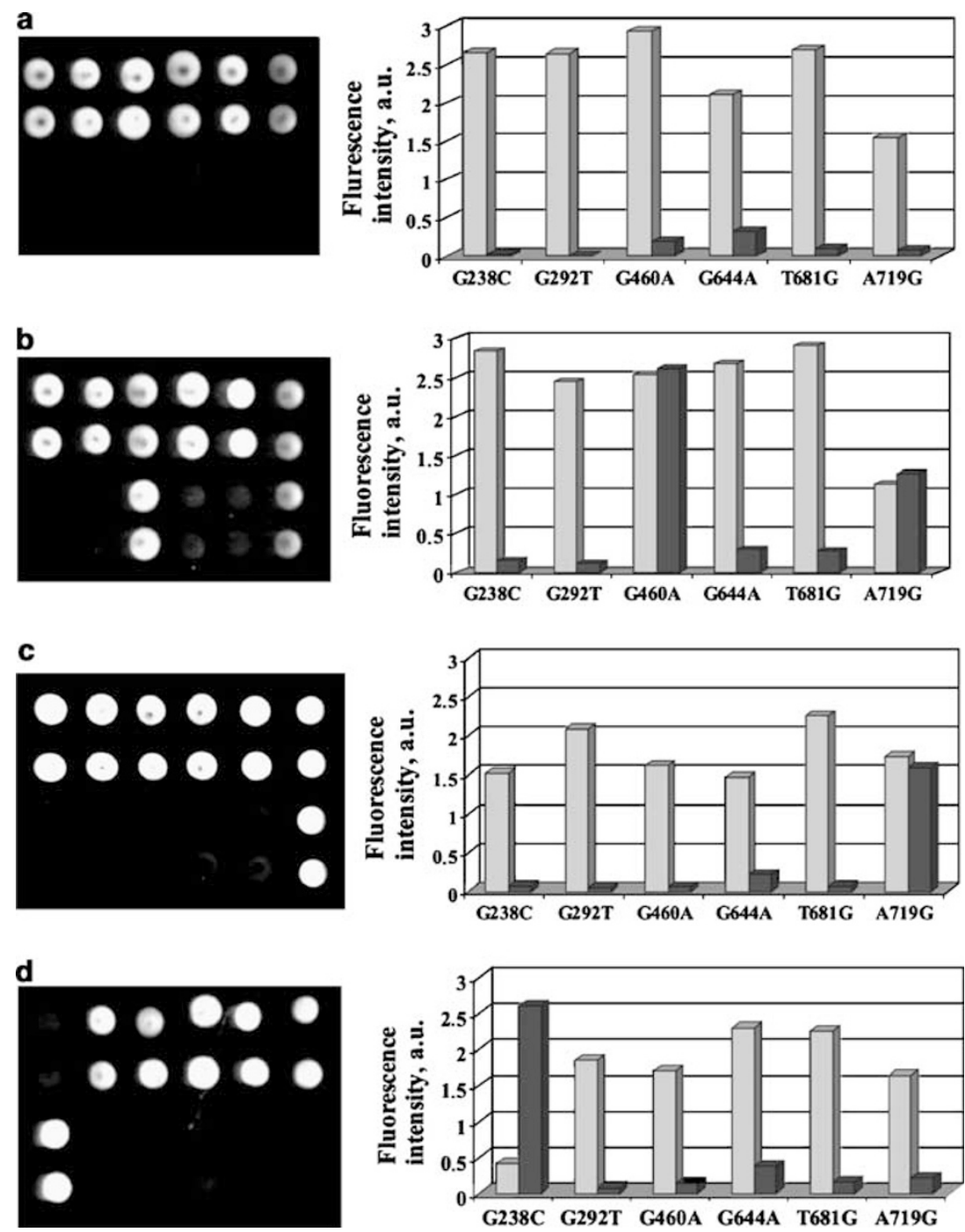

Figure 2 Biochip TPMT analysis of patients with different genotypes. Hybridization patterns (on the left) and histograms (on the right): (a) * $1 /{ }^{*} 1$, (b) ${ }^{*} 1 /{ }^{*} 3 A$, (c) ${ }^{*} 1 /{ }^{*} 3 C$, and (D) ${ }^{*} 2 /{ }^{*} 2$. The bright spots in the hybridization patterns correspond to outstanding peaks on the histograms. The signals from identical probes (rows $A-A^{\prime}$ and $B-B^{\prime}$ ) were averaged in the histograms.

\section{Data analysis and genotyping}

The method of analysis is based on the difference in signal intensity between perfect and imperfect duplexes formed by fluorescently labeled DNA sample and the probes immobilized in gel pads. The brightest fluorescent signal corresponded to the perfectly matched duplex formed by oligonucleotide and hybridized DNA target. Oligonucleotides in the upper gel pads in each column (A1-A6) match the wild-type sequence, that is, they form perfect duplexes with the wild-type target DNA. Oligonucleotides in the B1-B6 rows form perfect duplexes with mutant alleles of TPMT. Figure 2 shows examples of hybridization patterns for different genotypes. Genotype assignment can be performed visually or by using the automated image analysis. The automated program compares the fluores- cence intensity of the gel pads that contain wild-type sequence-specific probes to that of the pads that contain mutant sequence-specific probes. An example of the dialog window is shown in Figure 3.

The input data for the analysis were obtained from measurements of fluorescence intensity $J_{m}=\left(I_{m}-I_{0}\right) /$ $\left(B_{m}-I_{0}\right)$. Here, $I_{m}$ was the intensity per unit area in the internal region of a pad, $B$ was the counterpart background intensity, $I_{O}$ was leakage current of registering device, and $m$ enumerated the pads on the chip $(m=1, \ldots, 24)$. The signal intensities of the duplicate probes were compared, and the samples in which the duplicates differed more than $20 \%$ were reanalyzed. The $J_{m}$ values were sorted and the reference gel pad was defined as the one that preceded a sharp increase in signal. The threshold values were 


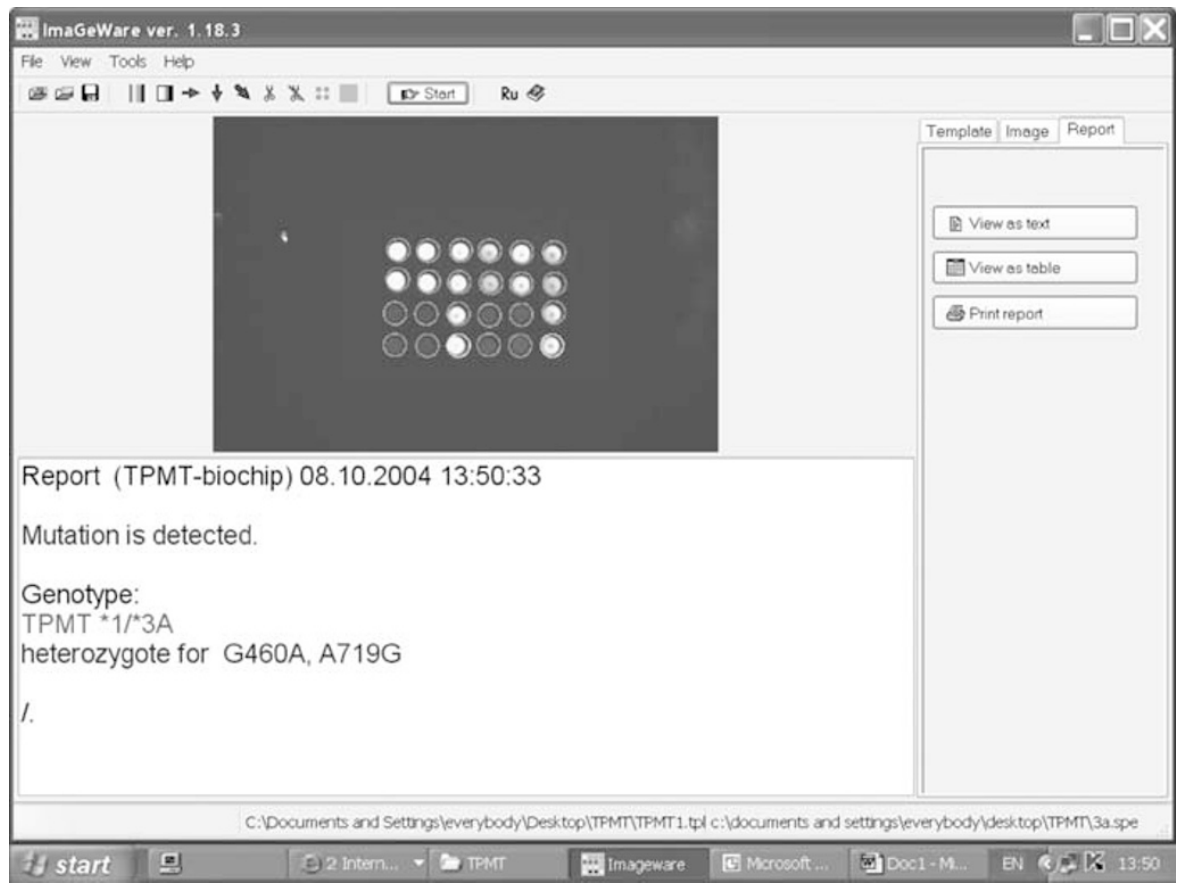

Figure 3 Example of automated analysis using Imageware ${ }^{\mathrm{TM}}$ software. The data were processed by using the algorithm described in the text, and the genotypes were assigned by automated image analysis.

Table 3 Comparative results of TPMT genotyping by PCR analysis and TPMT biochip technology

\begin{tabular}{|c|c|c|c|c|c|c|}
\hline \multirow{2}{*}{ Genotype } & \multirow{2}{*}{ Allele } & \multirow{2}{*}{ SNP } & \multicolumn{3}{|c|}{ Method } & \multirow{2}{*}{ Concordance } \\
\hline & & & $P C R$ & Biochip first operator & Biochip second operator & \\
\hline \multirow{4}{*}{$\begin{array}{l}\text { Wild-type } \\
\text { Heterozygote }\end{array}$} & $* 1 / * 1$ & - & 43 & 43 & 43 & 100 \\
\hline & $* 1 / * 2$ & G238C & 1 & 1 & 1 & 100 \\
\hline & ${ }^{*} 7 / * 3 A$ & G460A, A719G & 12 & 12 & 12 & 100 \\
\hline & $* 7 / * 3 C$ & G460A & 2 & 2 & 2 & 100 \\
\hline
\end{tabular}

established statistically for each pair 'perfect probemismatch probe' after approximately 50 hybridization patterns had been processed. A gel pad was considered to have a positive signal if its fluorescence intensity exceeded the value of the reference pad signal intensity $\times$ threshold value $J_{p} \geq J_{m}{ }^{*} T r h_{g r}$, where $T h r_{g r}$ was the threshold value for each pair 'perfect probe-mismatch probe'. If the signals in both pads (with normal and mutant probes) exceeded the threshold and the signals differed by a factor less than two, both signals were considered positive and the heterozygous genotype was assigned. If none of the signals in the column was positive, PCR amplification of the corresponding exon was assumed to have failed, and the sample was re-amplified. The main cause of PCR failure was the poor quality of isolated DNA, and in these cases the patient's DNA was re-isolated.

\section{Results \\ TPMT genotyping of control samples}

In blind experiments, we tested 58 DNA samples of known genotypes to assess the reliability and accuracy of the genotyping protocol. Reproducibility of the method was evaluated by two different operators performing the TPMTbiochip test in two independent series of experiments. All samples showed full agreement between the biochip-based approach and the PCR method (Table 3). The operator-tooperator reproducibility using control samples was $100 \%$. The $95 \%$ confidence interval of the probability that the two methods disagree is $(0-0.057)$, on the basis of the binomial distribution.

\section{Population screening}

Seven hundred blood samples were collected as part of a project to characterize TPMT genetic polymorphisms in the 
Russian Federation: 280 from patients with acute lymphoblastic leukemia, acute myeloid leukemia, or non-Hodgkin's lymphoma and 420 from healthy donors or patients with gastroenteric diseases. The patients were from different parts of Russia, and most of them were of the Eastern European ethnic group. Six inactivating mutations of the TPMT gene (G238C, G292T, G460A, G644A, T681G, A719G) were identified by using TPMT biochips. The 700 samples were analyzed by three operators. The first 400 samples were divided equally between two operators who performed the TPMT-biochip analyses independently. Among these 400 samples, the program failed to determine genotype and asked to repeat the analysis in 16 cases. For 11 of these 16 cases, the DNA was re-isolated from the frozen cells. The repeated analysis was then performed successfully. All samples with mutant genotypes determined by one operator were blindly analyzed by another operator together with several samples of wild-type genotype. Seventy samples required such crossgenotyping, and discrepancy between two operators was found in one case. After additional examination, the correct genotype was determined. Thus, the operator-to-operator reproducibility in population screening was about $99 \%$.

The last 300 samples were analyzed by the third operator. In nine of these 300 samples, the program failed to determine the genotype the first time and asked to repeat the analysis. In seven of these nine cases, the DNA was reisolated from the frozen cells. After the genotyping was complete, a total of 55 samples (all samples with mutant genotypes together with a number of wild-type samples) had been analyzed repeatedly by the same operator. All previously defined genotypes were confirmed in this repeat testing. Thus, the repeatability of the analysis can be considered to be $100 \%$.

As a result of testing, 37 individuals (5.3\%) were found to have genotype ${ }^{*} 1 /{ }^{*} 3 A$, five $(0.7 \%)$ had ${ }^{*} 1 /{ }^{*} 3 C$ and two $(0.3 \%)$ had ${ }^{*} 1 /{ }^{*} 2$. The remaining 656 individuals $(93.7 \%)$ had the wild-type genotype ${ }^{*} 1 /{ }^{*} 1$ (Table 4 ). No homozygous ${ }^{*} 2,{ }^{*} 3 A$, or ${ }^{*} 3 C$ genotypes were found, and no mutant genotypes ${ }^{*} 3 B,{ }^{*} 3 D,{ }^{*} 7$, or ${ }^{*} 8$ were found. The estimated allelic frequency was $96.8 \%$ (95\% CI, 95.8-97.7) for wild-type allele TPMT*1 (1356/1400) and 3.2\% (95\% CI, 2.3-4.2) for all variant alleles (44/1400). The frequency of specific variant alleles was $2.6 \%$ for $T P M T * 3 A(37 / 1400)$, $0.36 \%$ for TPMT *3C (4/1400), and $0.14 \%$ for $T P M T * 2(2 /$ 1400) (see also Table 5).

Table 4 Genotype frequencies in the Russian population

\begin{tabular}{lrc}
\hline TPMT genotype & Number & Genotype frequency (\%) (95\% CI) \\
\hline${ }^{*} 1 /{ }^{*} 1$ & 656 & $93.7(91.7-95.4)$ \\
${ }^{*} 1 /{ }^{*} 3 A$ & 37 & $5.3(3.7-7.2)$ \\
${ }^{*} 1 /{ }^{*} C$ & 5 & $0.7(0.2-1.6)$ \\
${ }^{*} 1 /{ }^{*} 2$ & 2 & $0.3(0-1.0)$ \\
\hline
\end{tabular}

\section{Discussion}

We have established a rapid DNA-microchip genotyping method that identifies clinically relevant inactivating TPMT alleles with high accuracy and reliability.

Determination of TPMT activity before the administration of thiopurine drugs is currently advocated, and recent studies have defined starting doses for 6-MP and its analogs on the basis of TPMT genotype. ${ }^{5}$ Although TPMT deficiency can be diagnosed by assays of erythrocyte TPMT activity, different factors, including patient age, renal function, receiving of $\mathrm{RBC}$ transfusion and thiopurine administration, may alter these results. ${ }^{15,16,21}$ Molecular genetic (PCR-based) methods are not affected by extraneous factors and offer a promising alternative to measurement of RBC TPMT activity. PCR-based methods require less than $1 \mu \mathrm{g}$ of DNA, which is the amount contained in approximately $100 \mu \mathrm{l}$ of whole blood. However, because each variant position of the TPMT gene is analyzed by using an individual pair of primers in AS-PCR, which is followed by additional enzyme treatment in the PCR-RFLP method, analysis for all significant TPMT polymorphisms requires many individual PCR reactions and is time- and resource-intensive.

The real-time PCR assay for the detection of TPMT*2, 3 , ${ }^{*} 4,{ }^{*} 5$, and ${ }^{*} 6$ has been described. ${ }^{22}$ However, the reagent and equipment costs for real-time PCR still limit its introduction into standard clinical laboratories. The pyrosequencing method has been proposed recently for genotyping of 10 single-nucleotide polymorphisms for TPMT* $1 S, * 2, * 3 A, * 3 B,{ }^{*} 3 C, * 3 D, * 4, * 5, * 6, * 7$, and *8. ${ }^{23}$ Pyrosequencing potentially has a wide use in the largescale identification of individual genotypes, but the cost of equipment will confine its application to large research centers.

The DNA-microchip technique described here helps to overcome certain drawbacks of PCR-based genotyping techniques. This approach for TPMT genotyping includes one multiplex PCR for all six mutations in one tube, followed by multiplex hybridization on a biochip. Taking only $1 \mu \mathrm{l}$ of patient DNA solution, it is possible to identify TPMT genotype. Even in real-time assay, proposed by Schütz et al., ${ }^{24}$ four capillaries per one patient were used. So, our procedure is obviously patient material saving. The hybridization was carried out overnight, because it was convenient in the parallel analysis of many samples. However, principally, the time of hybridization can be reduced up to $3 \mathrm{~h}$ without worsening of discrimination ratio between perfect and mismatch duplexes. More noticeably, the time-saving aspect of biochip-based analysis is revealed in high-throughput genotyping. Conventional PCR methods usually require post-PCR analysis, like restriction and electrophoresis or sequencing. In real-time PCR assay, the reaction had a run time of about $1 \mathrm{~h}$, but the genotype assignment was carried out after manual estimation of melting curves. $^{22}$ The biochip analysis using 
Table 5 Variant TPMT allele frequencies in the Russian Federation compared with other populations

\begin{tabular}{|c|c|c|c|c|c|}
\hline \multirow[t]{2}{*}{ Population } & \multirow[t]{2}{*}{ Total number of alleles } & \multicolumn{3}{|c|}{ Allele frequency in \% (95\% Cl) } & \multirow[t]{2}{*}{ Reference } \\
\hline & & $T P M T^{*} 3 A$ & $T P M T^{*} 3 C$ & $T P M T * 2$ & \\
\hline Russian Federation & 1400 & $2.6(1.9-3.6)$ & $0.36(0.11-0.83)$ & $0.14(0-0.5)$ & Present study \\
\hline Polish & 716 & $2.7(1.5-3.9)$ & $0.1(0-0.3)$ & $0.4(0-0.9)$ & Kurzawski et $a 1^{25}$ \\
\hline British & 398 & $4.5(2.4-6.6)$ & $0.3(0-1.9)$ & $0.4(0-1.2)$ & McLeod et $\left.a\right|^{26}$ \\
\hline American white & 564 & $3.2(1.7-4.6)$ & $0.17(0-0.5)$ & $0.17(0-0.5)$ & Hon et $a l^{14}$ \\
\hline African American & 496 & $0.8(0-1.6)$ & $2.4(1.1-3.8)$ & $0.4(0-1.0)$ & Hon et $a l^{14}$ \\
\hline Saami & 388 & 0 & $3.3(1.5-5.1)$ & 0 & Loennechen et $\left.a\right|^{27}$ \\
\hline Kenyan & 202 & 0 & $5.4(2.3-8.5)$ & 0 & McLeod et $a l^{26}$ \\
\hline Ghanaian & 434 & 0 & $7.6(5.0-10.0)$ & 0 & Ameyaw et $a 1^{28}$ \\
\hline Taiwanese & 498 & 0 & $0.6(0-1.3)$ & 0 & Chang et $a l^{29}$ \\
\hline Chinese & 384 & 0 & $2.3(0.8-3.8)$ & 0 & Collie-Duguid et $a l^{30}$ \\
\hline
\end{tabular}

portable biochip analyzer takes about 1 min per one biochip, including fully automatic image analysis and genotype assignment. Tens of samples can be analyzed simultaneously in our assay under highly standardized conditions.

In three-dimensional gel pads of microchips, as compared to two-dimensional spots, the local concentration of each oligonucleotide probe is higher because of the greater immobilization capacity of a gel. ${ }^{18}$ This leads to an increased fluorescence signal; as a result, the hybridization patterns can be visualized by using not only highresolution devices but also a portable chip-reader. ${ }^{20}$ The simplicity of the analysis and the relatively low cost of equipment offer some advantages over real-time PCR and pyrosequencing. The prime cost of small diagnostic biochips manufactured by gel-based biochip technology is around \$1-2. The quantity of each fluorescent primer used in one reaction is $10 \mathrm{pmol}$, so if they are supplied in a commercial kit, the price for one genotyping for all six mutations would be reasonable and undoubtedly available for small clinical laboratories.

The recognition of mutations occurs during allelicspecific hybridization of target DNA with complementary oligonucleotide probes. Three-dimensional biochips allow performing the analysis of melting curves, as well as hybridization kinetics analysis at chosen temperature. ${ }^{24}$ Usually such analysis is used as a preliminary step to optimize the hybridization conditions for a definite set of probes to provide the best discrimination ratio between perfect and mismatch duplexes. It is considered that the correct recognition of positive spots using microarrays is possible when the fluorescence signal exceeds more than 1.5 to two-fold the background signal. As we can see on diagrams (Figure 2), the discrimination ratio between positive and negative spots for each pair of wild-type mutation probes is ten folds or more. Thus, the conditions of hybridization were optimized to provide the highest reliability of the analysis. The accuracy and reliability of the method was estimated as $100 \%$ : we observed complete agreement between the results obtained with biochips and with standard methods analyzing 58 control samples. It was also proved in cross-analyzing of clinical samples, where the operator-to-operator reproducibility and repeatability of the analysis was approximately $99 \%$.

Many (potentially all) pharmacologically important polymorphisms can be analyzed simultaneously by the DNA-microchip technique. The addition of new mutations does not significantly increase the cost of analysis. The reason we did not include all known variants in our assay was that most of these variations are unique and some are of a completely different ethnic origin. We found no individuals who had the rare ${ }^{*} 3 D,{ }^{*} 7$ or ${ }^{*} 8$ alleles included in the assay. Previous analysis of TPMT genotype-phenotype relationship showed that the overall concordance rates of different population studies vary between 76 and $89 \%$. At the same time, it was found that testing for very rare mutant alleles does not significantly enhance the reliability of TPMT genotyping for intermediate methylators. ${ }^{8}$ More important could be the search for new mutations, which will be stimulated by introduction of the TPMT-biochip test. Retrospective analysis of clinical intolerance of 6-MP in patients with leukemias, together with TPMT genotyping of common deficient alleles, will help us to identify individuals who have none of these polymorphisms but are poor 6-MP metabolizers and who therefore may be carriers of new mutations.

The TPMT*3B allele was not detected among 1400 studied alleles and therefore is rare, if present at all, in the Russian population. For that reason, it is unlikely that any of the 37 subjects genotyped as ${ }^{*} 1 /{ }^{*} 3 A$ were actually ${ }^{*} 3 B /{ }^{*} 3 C$ compound heterozygotes; in our study, we assumed that subjects heterozygous for both the G460A and A719G mutations had genotype * $1 /{ }^{*} 3 \mathrm{~A}$.

The frequency of TPMT variant alleles has been reported in a variety of ethnic groups ${ }^{25-30}$ (see Table 5). We found $6.3 \%$ of the Russian Federation study group to have TPMTdeficient genotypes, and the total frequency of deficiency alleles was $3.2 \%$. TPMT ${ }^{*} 3 A$ was the prevalent mutant allele 
in Russia, as in European and white American populations, and composed $86 \%$ of all variant alleles, but the population frequency of $T P M T^{*} 3 A$ in Russia was noticeably lower $(2.6 \%)$ than in the British population $(4.5 \%)^{25}$ or among white Americans (3.2\%). ${ }^{13}$ The frequency seems to be similar to that in other Slavic populations, such as the Polish $(2.7 \%) .^{25}$

These results show the feasibility of patient screening for the most prevalent TPMT-deficiency alleles by new biochip technology so that those who require a substantial reduction in thiopurine dosage can be identified.

\section{Acknowledgements}

We thank Edward Kreindlin, Kirill Evseev, and Valentina Chupeeva for manufacture of the microchips and Sergei Surzhikov and Irina Grechishnikova for oligonucleotide synthesis.

This work was supported by the St Jude Children's Research Hospital International Outreach Program and by the American Lebanese Syrian Associated Charities (ALSAC).

\section{References}

1 Remy CN: Metabolism of thiopyrimidines and thiopurines: Smethylation with $S$-adenosylmethionine transmethylase and catabolism in mammalian tissues. J Biol Chem 1963; 238: 1078-1084.

2 Weinshilboum RM, Sladek SL: Mercaptopurine pharmacogenetics: monogenic inheritance of erythrocyte thiopurine methyltransferase activity. Am J Hum Genet 1980; 32: 651-662.

3 Elion GB: The purine path to chemotherapy. Science 1989; 244: $41-47$.

4 Krynetski EY, Tai HL, Yates CR et al: Genetic polymorphism of thiopurine $S$-methyltransferase: clinical importance and molecular mechanisms. Pharmacogenetics 1996; 6: 279-290.

5 Krynetski E, Evans WE: Drug methylation in cancer therapy: lessons from the TPMT polymorphism. Oncogene 2003; 22: 7403-7413.

6 Evans WE: Pharmacogenetics of thiopurine $S$-methyltransferase and thiopurine therapy. Ther Drug Monit 2004; 26: 186-191.

7 Krynetski EY, Schuetz JD, Galpin AJ, Pui CH, Relling MV, Evans WE: A single point mutation leading to loss of catalytic activity in human thiopurine S-methyltransferase. Proc Natl Acad Sci USA 1995; 92: 949-953.

8 Schaeffeler E, Fischer C, Brockmeier D et al: Comprehensive analysis of thiopurine S-methyltransferase phenotype-genotype correlation in a large population of German-Caucasians and identification of novel TPMT variants. Pharmacogenetics 2004; 14: 407-417.

9 Szumlanski C, Otterness D, Her C et al: Thiopurine methyltransferase pharmacogenetics: human gene cloning and characterization of a common polymorphism. DNA Cell Biol 1996; 15: 17-30.

10 Yates CR, Krynetski EY, Loennechen T et al: Molecular diagnosis of thiopurine $S$-methyltransferase deficiency: genetic basis for azathioprine and mercaptopurine intolerance. Ann Intern Med 1997; 126: 608-614.

11 Otterness D, Szumlanski C, Lennard L et al: Human thiopurine methyltransferase pharmacogenetics: gene sequence polymorphisms. Clin Pharmacol Ther 1997; 62: 60-73.

12 Spire-Vayron de la Moureyre C, Debuysere H, Sabbagh N et al: Detection of known and new mutations in the thiopurine
S-methyltransferase gene by single-strand conformation polymorphism analysis. Hum Mutat 1998; 12: 177-185.

13 Hon YY, Fessing M, Pui CH, Relling MV, Krynetski EY, Evans WE: Polymorphism of the thiopurine $S$-methyltransferase gene in African-Americans. Hum Mol Genet 1999; 8: 371-376.

14 McLeod HL, Lin JS, Scott EP, Pui CH, Evans WE: Thiopurine methyltransferase activity in American white subjects and black subjects. Clin Pharmacol Ther 1994; 55: 15-20.

15 Thervet E, Anglicheau D, Toledano N et al: Long-term results of TMPT activity monitoring in azathioprine-treated renal allograft recipients. J Am Soc Nephrol 2001; 12: 170-176.

16 Cheung ST, Allan RN: Mistaken identity: misclassification of TPMT phenotype following blood transfusion. Eur J Gastroenterol Hepatol 2003; 15: 1245-1247.

17 Otterness DM, Szumlanski CL, Wood TC, Weinshilboum RM: Human thiopurine methyltransferase pharmacogenetics. Kindred with a terminal exon splice junction mutation that results in loss of activity. J Clin Invest 1998; 101: 1036-1044.

18 Kolchinskii AM, Griadunov DA, Lysov I et al: Microchips based on three dimensional gel cells: history and perspective. Mol Biol (Mosk) 2004; 38: 5-16.

19 Rubina AY, Pan'kov SV, Dementieva EI et al: Hydrogel drop microchips with immobilized DNA: properties and methods for large-scale production. Anal Biochem 2004; 325: 92-106.

20 Bavykin SG, Akowski JP, Zakhariev VM, Barsky VE, Perov AN, Mirzabekov AD: Portable system for microbial sample preparation and oligonucleotide microarray analysis. Appl Environ Microbiol 2001; 67: 922-928.

21 Lennard L, Chew TS, Lilleyman JS: Human thiopurine methyltransferase activity varies with red blood cell age. Br J Clin Pharmacol 2001; 52: 539-546.

22 Schutz E, von Ahsen N, Oellerich M: Genotyping of eight thiopurine methyltransferase mutations: three-color multiplexing, 'two-color/shared' anchor, and fluorescence-quenching hybridization probe assays based on thermodynamic nearestneighbor probe design. Clin Chem 2000; 46: 1728-1737.

23 Okada Y, Nakamura K, Wada M et al: Genotyping of thiopurine methyltransferase using pyrosequencing. Biol Pharm Bull 2005; 28: $677-681$.

24 Sorokin NV, Chechetkin VR, Livshits MA et al: Discrimination between perfect and mismatched duplexes with oligonucleotide gel microchips: role of thermodynamic and kinetic effects during hybridization. J Biomol Struct Dyn 2005; 22: 725-734.

25 Kurzawski M, Gawronska-Szklarz B, Drozdzik M: Frequency distribution of thiopurine $S$-methyltransferase alleles in a polish population. Ther Drug Monit 2004; 26: 541-545.

26 McLeod HL, Pritchard SC, Githang'a J et al: Ethnic differences in thiopurine methyltransferase pharmacogenetics: evidence for allele specificity in Caucasian and Kenyan individuals. Pharmacogenetics 1999; 9: 773-776.

27 Loennechen T, Utsi E, Hartz I, Lysaa R, Kildalsen H, Aarbakke J: Detection of one single mutation predicts thiopurine $S$-methyltransferase activity in a population of Saami in northern Norway. Clin Pharmacol Ther 2001; 70: 183-188.

28 Ameyaw MM, Collie-Duguid ES, Powrie RH, Ofori-Adjei D, McLeod HL: Thiopurine methyltransferase alleles in British and Ghanaian populations. Hum Mol Genet 1999; 8: 367-370.

29 Chang JG, Lee LS, Chen CM et al: Molecular analysis of thiopurine $S$-methyltransferase alleles in South-east Asian populations. Pharmacogenetics 2002; 12: 191-195.

30 Collie-Duguid ES, Pritchard SC, Powrie RH et al: The frequency and distribution of thiopurine methyltransferase alleles in Caucasian and Asian populations. Pharmacogenetics 1999; 9: $37-42$. 